\title{
Development of a Predictive Model of Elderly Patients at Risk of Future Hospital Admission at Primary Care Centres in Valencia (Spain)
}

\author{
Ascensión Doñate-Martínez \\ Francisco Ródenas-Rigla \\ Jorge Garcés-Ferrer \\ Polibienestar Research Institute - University of Valencia
}

\begin{abstract}
This paper presents the development of a new predictive model of elders at risk of suffering hospital admissions in the subsequent year in Valencia (Spain), based on primary care experts' discussions and consensus. The study involves three main stages. Firstly, Focus Group methodology with six primary care experts to design the first set of variables of the model. Subsequently, two retrospective studies to analyse the performance of the selected variables in a pilot sample $(n=107)$ and to design the predictive model in a development sample $(n=343)$. Data was collected from electronic medical records and consulting the professional of reference. Logistic regression analysis identified five variables as predictors of hospital admissions during the subsequent year of the development cohort: diagnosis of chronic heart diseases, chronic respiratory diseases, diabetes, presence of palliative care and number of previous visits to the hospital emergency department. A risk scoring system was developed for each patient from 0 to 1 , with a cut-off point of 0.5 . The model had a sensitivity of $42 \%$, specificity of $96 \%$ and AUC of 0.764 . Our predictive model identifies with moderate efficiency elderly patients at risk of suffering future hospital admissions. Additionally, this first screening could be extended through a second phase aimed to assess social variables which are very relevant in the current economic context in Spain. Further research is needed to validate these results with larger samples, and to explore their applicability in other health and social care settings.
\end{abstract}

Keywords: Risk prediction model; primary care; elderly; future hospital admissions; chronic diseases

\section{Introduction}

The care and management of chronic diseases - those with a long duration and generally with slow progression - is one of the big challenges that public healthcare systems are currently facing within developed countries. In Spain, chronic diseases represent around $70 \%$ of the total costs in healthcare (García-Goñi et al., 2012) and are associated with a high use of several healthcare services and resources, such as visits to general practitioners (GPs), hospital admissions, pharmacological treatments or long-term care (LTC).

The approaches to these types of diseases are complicated by the fact that most of these patients do not suffer a unique chronic condition, but they present several of them at the same time; which is known as multimorbidity. Moreover, cases of multimorbidity are strongly associated with age (e. g. Salisbury et al., 2011). For instance, a study carried out in a sample of Spanish adults shows that the group of persons aged 65 and over presented the highest prevalence of multimorbidity; concretely, $67.3 \%$ of women and $52.9 \%$ of men (Garin et al., 2014).

In this regard, elderly people do have a high number of visits to GPs at primary care centres as they suffer more chronic conditions than other groups of population (Salisbury et al., 2011). However, according to a systematic review carried out by Sinnot et al. (2013), the current model of primary care is fragmented and lacks a patient-oriented approach, which does not facilitate an efficient management or an appropriate care of chronic patients. It is necessary that the model addresses an individualized perspective with special focus in continuity care (Garcés et al., 2011). Nonetheless, the identification of the most vulnerable patients in need of a more specific and comprehensive care is not always simple, so tools or strategies are required that facilitate this task to GPs in their daily work.

The systematic use of stratification tools and prediction models can be useful and support GPs in the decision-making processes, especially regarding elderly people with multimorbidity (Orueta et al., 2013). These types of initiatives would 
enable early implementation of intervention or prevention programmes to avoid adverse situations that would foster: (a) the support to GPs in the management of patients with more efficiency according to their clinical profile; and (b) savings for the system related to the use of health resources that these patients imply, such as hospital admissions.

In the current literature there is a wide number of population stratification tools aimed to identify patients at risk in accordance with different output variables; for instance, risk of frailty (Sternberg et al., 2011), individual risk of high healthcare cost (Coderch et al., 2014) or risk of suffering future hospital admissions (FHA) (Kansagara et al., 2011). Avoiding emergency hospital admissions in elderly population is a major interest for public administrations. Thus, early identification of profiles of patients at risk may facilitate the implementation of interventions to save potential costs related to healthcare utilization (Lehnert et al., 2011) and to avoid and/or decrease the functional decline and impairment of quality of life and physical and cognitive status in elderly people (Boltz et al., 2012; Merino \& Cruz-Jentoft, 2012).

In previous studies, the author has implemented stratification tools - originally developed and validated in the United States (USA) - in a Spanish sample of elderly patients using electronic health information systems (EHIS) as main source of data. Results showed a moderate efficiency in the identification of elderly patients at risk of suffering FHA (Doñate-Martínez et al., 2014). In spite of that study, it meant a starting point for the application of these types of strategies in the author's context (Ródenas et al., 2014), it is important to take into consideration the limitations associated to the use and extrapolation of tools in contexts that are different to the original one. The features of each healthcare system impact on numbers related to clinical variables (e. g. visits to primary care centres or emergency departments) and, therefore, to the results derived from stratification.

Thus, the objective of this study was the development of a new predictive model of elderly patients at primary care services from the Valencian Healthcare System (Spain) according to their risk level of suffering hospital admissions in the subsequent year.

\section{METHODOLOGY}

\section{1. Overall study design}

\section{Design}

The stratification model was developed between May 2014 and November 2015 in three main phases. In a first step, it was organized several sessions of focus groups (FG) with the participation of primary care professionals aimed to design the first set of variables for the model. In the second phase the preliminary version of the model was piloted through a retrospective cohort study in order to analyse its performance in a small sample from our study setting. Finally, based on the results of the previous step, a refined set of variables was implemented in a larger sample following a retrospective cohort design.

\section{Setting}

The study was carried out in the Comprehensive Healthcare Centre of Burjassot in Valencia (Spain), which combines primary and specialized care. In this municipality the population that was 65 years old and over were 6,905 people in 2013. The activity related to primary care in this municipality in 2012 is summarized in 90,312 visits to general medicine, 11,569 to nursing and 1,366 in social work services (AVS, 2013). The hospital of reference of this centre is the Hospital Universitario Arnau de la Ribera, which received a total of 14,338 admissions in $2013 ; 67.31 \%$ out of them were urgent (AVS, 2014).

\section{Ethical issues}

The project was approved by the Ethical Committee of the Hospital Arnau de Vilanova. During all phases of the study the data collection was undertaken by primary care professionals involved and the subsequent handling and statistical analysis was carried out after removing any type of personal data. In the second and third phases informed consents were not 
requested to patients as data was collected following a retrospective revision of clinical and administrative records of clinical histories.

\section{2. Stage 1 - Focus Groups: selection of variables}

\section{Participants}

Six primary health care experts from different fields (general medicine, nursing and social work) - with strong experience dealing with older people, chronicity and LTC - participated in different sessions of FG.

\section{Organization of the sessions}

Five sessions of FG took place aimed to agree and design a list of potential items to be included in the stratification model of patients. Every session lasted around 90 minutes and took place in the Comprehensive Healthcare Centre of Burjassot (Valencia). Sessions were coordinated and conducted by a researcher with previous experience in stratification models. Discussions were recorded on a digital recorder - after previous agreement of experts. A second facilitator also took notes on observations, summaries and reflections derived from the discussions.

Discussions were structured, so for every session organizers prepared in advance materials and defined a goal to be achieved. After each meeting organizers analysed the content recorded and in the following session they shared main results and consensus obtained to promote experts' commitment and motivation. Table 1 specifies the protocol followed along the FG and the main goals obtained in every session. In some sessions the Nominal Group Technique (NGT) was used to achieve consensus on key points for the scheduled discussions.

\section{Table 1. FG protocol (6 experts)}

\begin{tabular}{|l|l|l|}
\hline Session & Task & Objective \\
\hline 1 & Introduction of the project, organizers and experts. & $\begin{array}{l}\text { To present the objectives and tasks of the study. } \\
\text { To establish the first contact of the working group and } \\
\text { rapport. }\end{array}$ \\
\hline $2 \& 3$ & $\begin{array}{l}\text { Study of } 10 \text { clinical cases (selected by experts) with a } \\
\text { profile characterized by: a) } 65 \text { years and over; b) } \\
\text { multiple chronic diagnoses; c) with and without previous } \\
\text { hospital admissions. }\end{array}$ & $\begin{array}{l}\text { To draw enabling and protective variables of suffering } \\
\text { FHA. }\end{array}$ \\
\hline 4 & $\begin{array}{l}\text { Presentation by the organizers of variables selected } \\
\text { from the analysis of sessions 2 and 3. } \\
\text { Assessment and prioritization by every expert of } \\
\text { variables according to: a) their rate in the prediction of } \\
\text { future hospital admissions; and b) relationships between } \\
\text { variables. } \\
\text { Share assessments and discussion. }\end{array}$ & $\begin{array}{l}\text { To reach an agreement and to select the most relevant } \\
\text { variables for the identification of patients at risk of suffering } \\
\text { FHA. }\end{array}$ \\
\hline 5 & $\begin{array}{l}\text { Presentation by the organizers of agreed variables at } \\
\text { session 4. } \\
\text { Discussion to define every variable and to establish how } \\
\text { to measure them. }\end{array}$ & To operationalize the selected variables. \\
\hline
\end{tabular}

\section{3. Stage 2 - Pilot cohort}

In the second stage a retrospective study was carried out to identify the variables - those previously detected and designed in the first stage - with a higher contribution in the prediction of hospital admissions in the subsequent 12 months.

\section{Target population and sample}

Target population of this study were patients aged 65 years and over attended by primary care services at the Comprehensive Healthcare Centre of Burjassot. 
The sample was screened and recruited through consecutive sampling from the quota of assigned patients of the six healthcare experts participating in the FG. Patients were selected from the available population which fulfilled the selection criteria on the established reference date (February 2013). Exclusion criteria for inclusion were: a) aged under $65 ; b$ ) absence of data at the EHIS; c) no permanent residence in Burjassot; d) exitus; e) being institutionalized; and f) hospital admissions in the subsequent 12 months not associated to long-term diagnosis (e. g. cataract) and/or programmed admissions.

Finally, the pilot sample was composed of 107 patients, with a sampling error of $2.3 \%$ yielding a $95 \%$ confidence level.

\section{Data collection}

Data related to independent variables were collected with reference date February 2013 using several sources:

Most of the information was collected through different EHIS of the Valencian Healthcare System available for primary care professionals:

Abucasis, with information related to clinical history, diagnostic tests, medical alerts, appointments, demographic variables, etc. ;

GAIA, which registers the prescribed medications to patients through electronic prescription; and

MDS (Minimum Data Set), which registers patients' discharges and associated information (main and secondary diagnosis, clinical and/or surgical procedures, etc. ).

Some information was gathered through consultation of the professional of reference (GP, nurse or social worker).

Finally, a search was carried out of hospital admissions of each patient during the subsequent 12 months at MDS. In this regard, the author knew if patients were admitted or not, the number of admissions and the length of stay in days of every admission.

Once all the data had been collected, any type of personal or identifying information was removed and was assigned a random number to each patient to preserve privacy.

\section{Statistical analysis}

The processing and statistical analysis of data collected during the whole study was done using PASW Statistics 22 software (SPSS). Firstly, descriptive analyses were made to characterize the sample according to the variables agreed through the FG. Subsequently, logistic regression analysis was conducted with the independent variables obtained in the FG to identify the most significant variables associated to FHA.

\section{4. Stage 3-Development cohort}

This third stage is also characterized by a retrospective study. In this case, on the basis of the findings of the previous phase, the objective was to develop the prediction model through an appropriate and accurate combination of the set of variables analysed in the previous stages.

\section{Target population and sample}

Target population and the exclusion criteria were the same than used in the pilot cohort (see Stage 2, at section 2. 3). The development sample was composed by 343 patients with a sampling error of $2.2 \%$ yielding a $95 \%$ confidence level. In this case, the sample was screened and recruited through quota sampling in order to distribute a representative number of patients with FHA for the subsequent logistic regression analyses.

\section{Data collection}

The set of variables included in this study was based on the results obtained in the previous stage: number of visits to emergency department (ED) at hospital, visits to ED at primary care centres, emergency visits at home and emergency phone calls to the primary care centre in the previous 12 months. Moreover, other variables that could be easily accessible from EHIS were included: sex, age and active diagnosis. 
The procedure for data collection of independent and dependent variables was the same as in the previous study. However, in this case the sources employed were only EHIS (Abucasis, GAIA and MDS).

\section{Statistical analysis}

Descriptive analyses were made to characterize the sample according to the variables studied.

Logistic regression analyses were performed to identify those variables with a higher contribution for the prediction of FHA; creating a risk score from 0 to 1 to describe the estimated probability of admission in the subsequent 12 months.

From results achieved by logistic regression, a predictive risk model was developed based on adjusted odds ratios (OR). For this purpose, the author randomly divided the sample in two groups. The first one included the $80 \%$ of the sample and was used to estimate the model with a $95 \%$ of confidence; the remaining $20 \%$ of the sample was used to validate the model.

The goodness of fit of the model was evaluated by Nagelkerke R-squared and Hosmer-Lemeshow tests, which determine the proportion of variance of the dependent variable explained by the model.

The predictive accuracy of the model was assessed through sensitivity, specificity, positive predictive value (PPV), negative predictive value (NPV) and the area under the receiving operating characteristic (ROC) curve (AUC).

Finally, the sample was divided into two groups (low and high risk) according to scores' of the predictive model. Comparisons between both groups were made using the t-test for normally distributed continuous variables or MannWhitney $\mathrm{U}$ test for non-normally distributed continuous variables; and Chi-square tests for categorical variables.

\section{RESULTS}

\section{1. Stage 1 - Focus Groups: selection of variables}

Six health and social care professionals from a primary care centre participated in five FG sessions. The output derived from these meetings was a list of potential variables to be tested for the development of the predictive model. Figure1 presents these variables and the source where to find the related data.

\section{Figure 1. Selected variables from FG for the development of the predictive model}

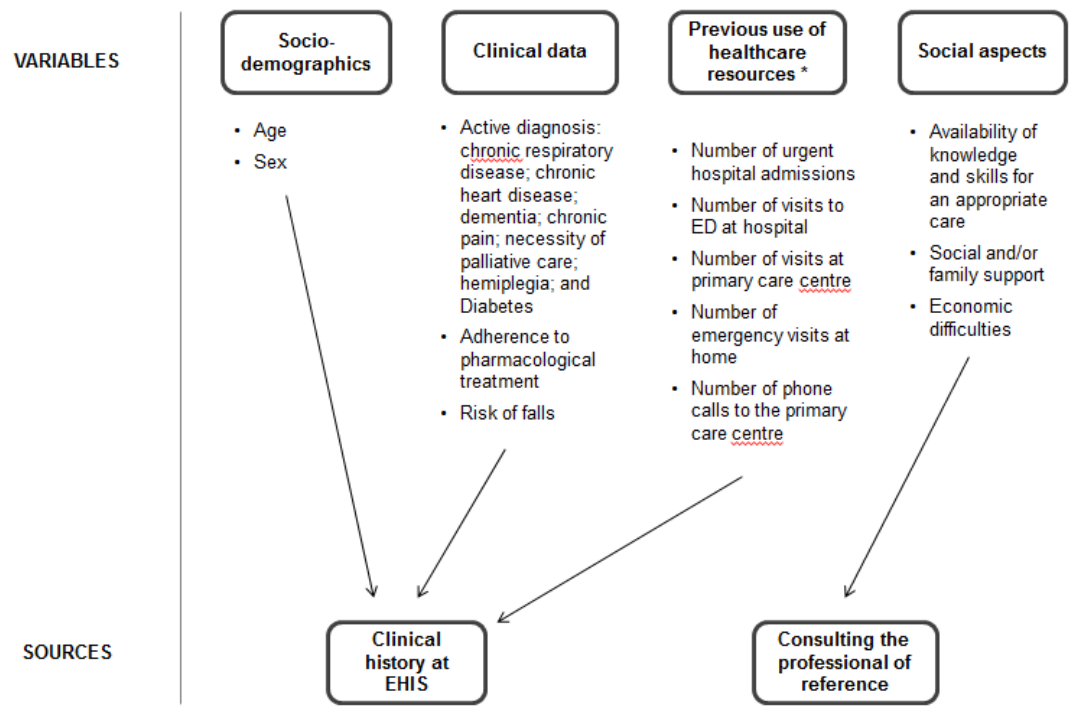

* The use of healthcare resources is referred to the previous 12 months 


\section{2. Stage 2 - Pilot cohort}

Table 2 shows dataset of the sample $(n=107)$ in which the first proposal of variables was tested. Average age was 77.05 \pm 6 years, and most of the sample was women (67.29\%).

The most prevalent diagnoses were diabetes (39. 25\%) and chronic heart conditions (31.78\%).

Out of 107 patients, $9(8.41 \%)$ suffered hospital admissions in the subsequent 12 months. The mean number of hospital admissions was $0.12 \pm 0.49$ and the length of stay was $7.08 \pm 6.22$ days. Most of the causes of 12-months admissions (44. $44 \%$ patients) were diagnosis derived from diabetes, as hypoglycaemia or diabetic foot.

\section{Table 2. Characteristics of pilot sample}

\begin{tabular}{|c|c|}
\hline Variables & $N=107$ \\
\hline \multicolumn{2}{|l|}{ Active diagnosis, $\mathrm{n}(\%)$} \\
\hline Chronic respiratory disease & $20(18.70)$ \\
\hline Chronic heart disease & $34(31.78)$ \\
\hline Dementia & $11(10.28)$ \\
\hline Chronic pain & $17(15.89)$ \\
\hline Palliative care & $4(3.74)$ \\
\hline Hemiplegia & 0 \\
\hline Diabetes & $42(39.25)$ \\
\hline Availability of knowledge and skills for an appropriate care, $n(\%)$ & $102(95.33)$ \\
\hline Adherence to pharmacological treatment, $n(\%)$ & $102(95.33)$ \\
\hline Risk of falls, $n(\%)$ & $47(43.93)$ \\
\hline Number of previous urgent hospital admissions, $\square$ (SD) & $0.20(0.52)$ \\
\hline Number of previous ED visits at hospital, $\square$ (SD) & $0.77(1.37)$ \\
\hline Number of previous visits at primary care centre, $\square$ (SD) & $1.54(2.81)$ \\
\hline Number of previous emergency visits at home, $\square$ (SD) & $2.21(9.81)$ \\
\hline Number of previous phone calls to the primary care centre, $\square$ (SD) & $0.17(0.57)$ \\
\hline Social and/or family support, $n(\%)$ & $89(83.18)$ \\
\hline Economic difficulties, $\mathrm{n}(\%)$ & $14(13.08)$ \\
\hline Age, $\square($ SD) & $77.05(6)$ \\
\hline \multicolumn{2}{|l|}{ Sex, $n(\%)$} \\
\hline Men & $35(32.71)$ \\
\hline Women & $72(67.29)$ \\
\hline
\end{tabular}


Logistic regression determined that 'number of previous visits to ED at hospital' [OR=913.52 ( $p<0.064]$ and 'number of previous emergency visits at home' $[\mathrm{OR}=0.008, p<0$. 092] were the variables most associated with hospital admissions within 12 months.

\section{3. Stage 3 - Development cohort}

In this last stage of the study, several logistic regression analyses were conducted including those variables that showed significance in the previous phase ('number of previous visits to ED at hospital' and 'number of previous emergency visits at home'). Other variables related to the use of primary care resources detected in the first stage were also taken into consideration but, in this case, only if they were urgent cases ('number of previous visits to ED at primary care centre' and 'number of previous emergency phone calls to the primary care centre'). Additionally, variables of 'active diagnosis', 'age' and 'sex' were included as researchers and experts from FG considered and agreed as relevant for clinical assessments and socio-demographic clusters.

Socio-demographic, clinical and use of resources data of the development sample $(n=343)$ are presented in Table 3. Mean age was $75.20 \pm 6.89$ years and $61.81 \%$ of the sample was women. Diabetes $(36.44 \%)$ and chronic heart conditions (29. $74 \%$ ) were the most prevalent conditions.

Out of 343 patients, $99(28.9 \%)$ suffered hospital admissions in the subsequent 12 months. The mean number of hospital admissions was $0.39 \pm 0.76$ and the length of stay was $3.76 \pm 14.35$ days.

Table 3. Characteristics of the development sample $(\mathrm{N}=343)$ and by risk categories

\begin{tabular}{|c|c|c|c|c|}
\hline Variables & $\begin{array}{l}\text { Total sample } \\
(n=343)\end{array}$ & $\begin{array}{l}\text { Low risk group }(0- \\
0.49) \\
(n=291)\end{array}$ & $\begin{array}{l}\text { High risk group }(0.5 \\
-1) \\
(n=52)\end{array}$ & $p$ \\
\hline \multicolumn{5}{|l|}{ Active diagnosis, $\mathrm{n}(\%)$} \\
\hline Chronic respiratory disease & $72(21)$ & $53(18.21)$ & $19(36.54)$ & 0.003 \\
\hline Chronic heart disease & $102(29.74)$ & $67(23.02)$ & $35(67.31)$ & $<0.001$ \\
\hline Dementia & $43(12.54)$ & $32(11)$ & $11(21.15)$ & 0.042 \\
\hline Chronic pain & $22(6.41)$ & $18(6.19)$ & $4(7.69)$ & 0.68 \\
\hline Palliative care & $15(4.37)$ & 0 & $15(28.85)$ & $<0.001$ \\
\hline Hemiplegia & $6(1.75)$ & $3(1.03)$ & $3(5.77)$ & 0.016 \\
\hline Diabetes & $125(36.44)$ & $100(34.36)$ & $25(48.08)$ & 0.058 \\
\hline $\begin{array}{l}\text { Number of previous urgent hospital } \\
\text { admissions, } \square \text { (SD) }\end{array}$ & $0.70(1.12)$ & $0.36(0.60)$ & $2.60(1.45)$ & $<0.001$ \\
\hline $\begin{array}{l}\text { Number of previous ED visits at primary } \\
\text { care centre, } \square(\mathrm{SD})\end{array}$ & $0.75(1.25)$ & $0.68(1.13)$ & $1.10(1.73)$ & 0.001 \\
\hline $\begin{array}{l}\text { Number of previous emergency visits at } \\
\text { home, } \square \text { (SD) }\end{array}$ & $0.15(0.52)$ & $0.09(0.40)$ & $0.47(0.90)$ & $<0.001$ \\
\hline $\begin{array}{l}\text { Number of previous emergency phone calls } \\
\text { to the primary care centre, } \square \text { (SD) }\end{array}$ & $0.09(0.42)$ & $0.04(0.24)$ & $0.40(0.87)$ & $<0.001$ \\
\hline Age, $\square(\mathrm{SD})$ & $75.20(6.89)$ & $74.58(6.72)$ & $78.65(6.87)$ & 0.589 \\
\hline \multicolumn{5}{|l|}{ Sex, n (\%) } \\
\hline Men & $131(18.19)$ & $111(38.14)$ & $20(38.46)$ & 0.97 \\
\hline
\end{tabular}




\begin{tabular}{|l|l|l|l|l|}
\hline Women & $212(61.81)$ & $180(61.86)$ & $32(61.54)$ & $42(80.77)$ \\
\hline $\begin{array}{l}\text { Cases with 12-months hospital admissions, } \\
\mathrm{n}(\%)\end{array}$ & $99(28.9)$ & $57(19.59)$ & $1.23(1.13)$ & $<0.001$ \\
\hline $\begin{array}{l}\text { Number of 12-months hospital admissions, } \\
(\mathrm{SD})\end{array}$ & $0.36(0.76)$ & $0.23(0.54)$ & $14.69(31.74)$ & $<0.001$ \\
\hline Length of stay in days, $\mathrm{L}(\mathrm{SD})$ & $3.76(14.35)$ & $1.81(6.37)$ & 001 \\
\hline
\end{tabular}

Table 4 shows the main details of the variables being part of the predictive model. Logistic regression analysis determined that the variables presence of 'chronic respiratory disease', 'chronic heart disease' and 'palliative care', and the 'number of previous visits to ED at hospital' were statistically significant as predictors. The diagnosis of 'palliative care' was the most significant predictor with an OR of 22. $53(95 \% \mathrm{Cl}, 2.70-188.60)$; and the 'number of previous visits to ED at hospital' was the weakest one with an OR of $1.82(95 \% \mathrm{Cl}, 1.39-2.37)$. 'Age', diagnosis of 'dementia', 'chronic pain' and 'hemiplegia', or the number of previous contacts with the primary care centre ('visits to the ED', 'emergency visits at home' or 'emergency phone calls') were not of any significant result on the regression analysis.

Table 4. Summary of variables included in the predictive model

\begin{tabular}{|l|l|l|l|}
\hline Variables & OR & $95 \% \mathrm{Cl}$ & $\mathrm{p}$ \\
\hline Chronic respiratory disease & 2.32 & $1.18-4.59$ & 0.015 \\
\hline Chronic heart disease & 2.10 & $1.13-3.91$ & 0.019 \\
\hline Palliative care & 22.53 & $2.70-188.60$ & 0.004 \\
\hline Diabetes & 1.94 & $1.06-3.54$ & 0.032 \\
\hline Number of previous visits to ED at hospital & 1.82 & $1.39-2.37$ & $<0.001$ \\
\hline
\end{tabular}

The percentage of variance explained by the final model was $31 \%$ (Nagelkerke's R2 $=0.31$ ). Moreover, the estimated risk showed very good agreement with the observed incidence (Hosmer-Lemeshow $\chi^{2}=1.24, p=0.975$ ).

The model determined a risk score from 0 to 1 for each patient, classifying patients as high risk of future hospital admission at a risk score threshold of 0.5 or higher. The model had a sensitivity of $42 \%$ and specificity of $96 \%$, and the PPV was $81 \%$ and the NPV $80 \%$. The Figure 2 shows the ROC curve illustrating the trade-off between sensitivity and 1-specificity for the model. The AUC was 0.76 .

Figure 2. ROC curve for presence or absence of future hospital admission based on risk scores derived from the predictive model

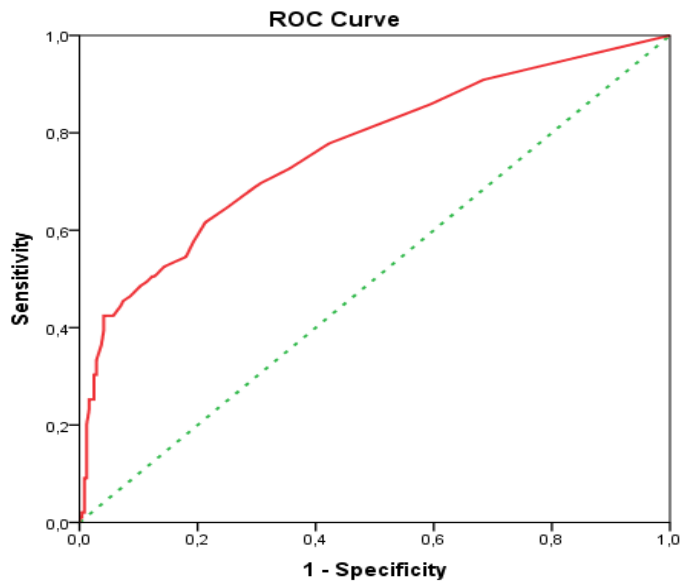


Table 3 shows baseline data on socio-demographics, health conditions and health service utilization measures, as well as data related to future hospital admissions for low- (risk scores 0-0. 49) and high-risk groups (scores 0. 5-1). The high-risk group (15. $16 \%$ of the sample) had significantly higher prevalence of chronic diseases (with the exception of 'chronic pain') and reported higher prior emergency visits' or contacts' (both to hospital, primary care centre, at home or emergency phone calls) rates. Low- and high-risk groups did not differ in the mean age or sex rates. Table 3 also presents data from the sample on the subsequent 12 months. In this regard, the high-risk group showed a significantly higher rate and mean of FHA, as well as more days of length of stay.

\section{DISCUSSION}

This paper presents the development of a new prediction model to identify elderly patients at risk of hospital admission in the subsequent 12 months using routine data from EHIS from the Valencian Healthcare System. For this purpose, the author followed a combined methodological approach using both qualitative and quantitative techniques. Thus, on the basis of different sessions of FG with a panel of primary care experts the set of variables were selected that subsequently were tested and analysed in two retrospective studies aimed to assess their predictive ability on FHA.

The model incorporates five predictor variables which are associated with an increased risk of hospital admission: diagnosis of chronic heart diseases, chronic respiratory diseases, diabetes, presence of palliative care and number of previous visits to ED at hospital. These findings are close to those variables found in other studies on the general population and on elderly people. For instance, "Probability of Repeated Admission" (Pra) and "The Community Assessment Risk Screen" (CARS) tools (Boult et al., 1993; Shelton et al., 2000) include as relevant variables diagnosis of different chronic conditions (such as diabetes or heart diseases), as well as previous use of hospital resources (admissions or ED visits).

The performance of the model was good, with acceptable ability to identify patients at high risk of hospital admission which really were admitted (sensitivity of $42 \%$ ) and excellent ability to identify patients at low risk which really did not suffer any admission (specificity of $96 \%$ ). The accuracy detecting patients was similar to other comparable studies (e. g. Hippisley Cox \& Coupland, 2013) or even higher (Billings et al., 2006; Lyon et al., 2007; Chandra et al., 2015) with reported AUC of 0.764 .

In our model, the presence of palliative care had a strong effect on the prediction of FHAs, with an OR of $22.53(p=0.04)$. In the current literature we did not find similar prediction models or tools considering this variable as relevant. However, palliative care has shown a strong association with the risk of death in hospital or soon after discharge (Cardona-Morrell \& Hillman, 2014; Cowen et al., 2014), since people receiving palliative care suffers a notable irreversible deterioration of health outcomes as well as in their quality of life.

The regression model derived a risk scoring system ranking each patient from 0 to 1 , with a cut-off point of 0.5 . The development sample was stratified following this threshold, so it was divided into two risk-groups. High-risk group (84. 84\%) differed significantly from the low-risk (15. 16\%) in almost all diagnosis and previous emergency visits' or contacts' measures. Moreover, high-risk patients suffered significantly more FHAs and they spent more days at hospital than lowrisk individuals. These numbers support the main goal and utility that author expected with the development of this predictive model and stratification system: to help primary care professionals in decision-making processes through early detection of vulnerable patients with a higher trend to use healthcare resources and, therefore, which mean higher costs for the administration.

The final predictive model is composed by variables that can be collected automatically from EHIS. In this way, as other stratification and predictive systems available in the literature (e. g. Billings et al., 2012), the associated algorithm could be easily introduced into the health administration system of the Valencia Region. Nevertheless, experts interviewed in the FG - carried out in the framework of this study - highlighted other kind of variables that usually are not registered within EHIS of special relevance to identify vulnerable elders. These variables are: 'availability of knowledge and skills for appropriate care', 'social and/or family support' and 'economic difficulties'. Firstly, due to the long duration and irreversible nature of chronic conditions it is vital that patients are empowered and confident in the self-management of their diseases with appropriate knowledge and skills adapted to their own needs. There is evidence suggesting that self-management education improves health outcomes and can reduce hospitalizations for some kind of chronic diseases (Bodenheimer et al., 2002). Secondly, social isolation and lack of social support may have negative impact on the health and wellbeing of elderly people (Hawton et al., 2011). Moreover, according to an exploratory study (Jakobsson et al., 2011), elders with low 
utilization of inpatient and outpatient care were characterized by having a larger social network or feeling less loneliness than those with higher consumption of these resources. So, it is very important that elders have some kind of social support by their circle of support (family and/or friends) or by social services from the public administration or private companies. And finally, Spain is currently facing a financial crisis which has entailed budget cuts in health; and pensioners suffer these effects through pharmaceutical and assistance co-payments (Aguilera et al., 2013). Moreover, older adults and elders have become the main source of economic support for the family due to the return of adult children to the parental home as a consequence of the lack of work opportunities and extremely high unemployment rates (Foessa \& Cáritas, 2013). These issues mean that many elders do not spend part of their pension or acquisitive power to acquire prescribed pharmacological and therapeutic treatments not covered by social security (as blood glucose test trips in the case of patients with diabetes), which may affect the stability of chronic conditions' symptomatology and higher rates of hospital admissions (FernándezRuiz et al., 2015).

Variables discussed in the above paragraph may have a relevant potential to identify vulnerable elderly patients, especially in the current context of financial crisis in Spain. For this reason, it would be interesting to propose a 2-phase stratification system, as other methods we find in the literature (Reuben et al., 2002). The first phase would entail the calculation of the developed algorithm through the use of EHIS; and the second one, the assessment of social variables by consulting the professional of reference.

From this comprehensive evaluation and screening, professionals may implement individualized care plans, which can potentially improve quality of care and reduce costs in comparison to usual population-based guidelines (Eddy et al., 2011). In order to guarantee these care pathways respond patients' clinical and social needs the decision-making should be shared by multidisciplinary case-management teams composed by different primary care professionals, as GPs, nurses and social workers (Garcés et al., 2013; Garcés \& Ródenas, 2015). According to the conclusions derived from a European Conference on Multimorbidity Policies (European Commission, 2015), these interventions should increase patient-centeredness and empowerment through a higher involvement of patients' and families in the care of their chronic conditions. Educative and training approaches should be introduced, as they are effective increasing patients' knowledge and skills, self-management of symptoms or self-efficacy (Barlow et al., 2002). Moreover, new information and communication technologies (ICTs) play a crucial role. In this line, a recent study focused on a telemonitoring programme addressed to chronic patients show that, after one-year of use, users became more aware of the importance of controlling their diseases and symptoms and improved their self-perceived health-related quality of life as well (Doñate-Martínez et al., 2016). Last but not least, continuity of care should be a common point in all care plans addressed to chronic patients - especially elders - as it is essential to guarantee quality of care over time. In this regard, higher continuity of ambulatory care has been associated with lower rates of preventable hospitalization in elderly Medicare beneficiaries (Bayliss et al., 2015).

Our study has several limitations that deserve mention. First, in spite of our study includes a large number of elders from a specific setting of Valencia (Burjassot), it is not representative of the whole elderly population in the Valencia Region. Secondly, pilot and development studies followed a retrospective design; however the use of unified EHIS enhances and guarantees the accuracy of the collected data, both independent variables and those to be predicted. Thirdly, there is an increasing interest of developing risk prediction tools aimed to detect adverse effects in a short period of time; within 30 days from a previous discharge (e. g. Fabbian et al., 2015). However, the authors' goal was to identify patients at risk allowing primary care professionals have enough time to implement the most appropriate care pathways to prevent FHAs in the following 12 months. Moreover, during this period of time it is favoured that the benefits of the established interventions are visible; recommendations to change lifestyles, introduction of new pharmacological treatments or modifications in previous ones, establishment of additional social services increasing patient quality of life, etc. And, finally, the model considered and included a limited number of predictors. It is possible that other variables could be useful as predictive factors, nevertheless we followed the opinion and consensus achieved by our panel of primary care experts, which are in line with those obtained by other authors.

\section{Conclusions}

In conclusion, our results suggest that our predictive model composed by a reduced number of variables agreed by primary care experts and collected from EHIS (automatically or manually by primary care professionals) identifies with a moderate level of efficiency elderly patients at risk of suffering FHAs. The algorithm associated to this model is intended to be introduced computationally in EHIS in order that healthcare professionals can carry out regular analysis of datasets containing specific quota to identify and alert high risk patients for further assessment of social variables and subsequent 
management. So, the screening of high risk patients is just the first step of a comprehensive and patient-centred strategy to improve both the quality of life of this profile of patients and also the quality of their management at primary care centres.

Future studies are needed to validate these results with a larger sample from the Valencia Region and other regions in Spain; as well as to explore their applicability in other health and social care settings, as hospitals or nursing homes.

\section{Acknowledgements}

Thanks to the Polibienestar Research Institute at the University of Valencia; the Valencian Ministry of Health (Agencia Valenciana de Salud); and the Comprehensive Healthcare Centre of Burjassot (Valencia).

The study presented in this paper received financing from, the Valencian Government through the project PrometeoOpDepTec Fase II (Project reference: PROMETEUII/2014/074) and the Spanish Ministry of Innovation and Competitiveness (Project reference: CSO2014-54490-R). A. Doñate-Martínez was supported by a predoctoral FPU fellowship of the Spanish Ministry of Education (AP2010-5354).

\section{References}

[1] Aguilera, J. C., de la Fuente, L., Martínez, A. \& Llopis, E. S. (2013). El impacto de la crisis en las condiciones de vida de las personas mayores. Colección Informes, 56. Fundación $1^{0}$ de Mayo: Madrid. (in Spanish) Accessed 05/12/2015.

[2] AVS (2013). Memoria 2012. Departamento de Salud Valencia-Arnau de Vilanova-Llíria. Available at: http://arnau. san. gva. es/documents/4084233/4155833/memoria_2012_definitiva_0. pdf (in Spanish) Accessed 24/08/2015.

[3] AVS (2014). Memoria 2013. Departamento de Salud Valencia-Arnau de Vilanova-Llíria. Available at: http://issuu. com/departamentoarnau/docs/memoria_2013 (in Spanish) Accessed 24/08/2015.

[4] Barlow, J., Wright, C., Sheasby, J., Turner, A. \& Hainsworth, J. (2002). Self-management approaches for people with chronic conditions: a review. Patient Education and Counseling, 48(2): 177-187.

[5] Bayliss, E. A., Ellis, J., Shoup, J. A., Zeng, C., McQuillan, D. \& Steiner, J. (2015). Effect of Continuity of Care on Hospital Utilization for Seniors With Multiple Medical Conditions in an Integrated Health Care System. The Annals of Family Medicine, 13: 123-129.

[6] Billings, J., Dixon, J., Mijanovich, T., \& Wennberg, D. (2006). Case finding for patients at risk of readmission to hospital: development of an algorithm to identify high risk patients. British Medical Journal, 333: 327-332.

[7] Billings, J., Blunt, I., Steventon, A., Georghiou, T., Lewis, G. \& Bardsley, M. (2012). Development of a predictive model to identify inpatients at risk of re-admission within 30 days of discharge (PARR-30). BMJ Open, 00.

[8] Bodenheimer, T., Lorig, K., Holan, H. \& Grumbach, K. (2002). Patient Self-management of Chronic Disease in Primary Care. The Journal of the American Medical Association, 288: 2469-2475.

[9] Boltz, M., Resnick, B., Capezuti, E., Shuluk, J. \& Secic, M. (2012). Functional Decline in Hospitalized Older Adults: Can Nursing Make a Difference? Geriatric Nursing, 33: 272-279.

[10] Boult, C., Dowd, B., McCaffrey, D., Boult, L., Hernandez, R., \& Krulewitch H. (1993). Screening elders for risk of hospital admission. Journal of the American Geriatrics Society, 41: 811-817.

[11] Cardona-Morrell, M. \& Hillman, K. (2014). Development of a tool for defining and identifying the dying patient in hospital: Criteria for Screening and Triaging to Appropriate aLternative care (CriSTAL). BMJ Supportive \& Palliative Care, 0: 1-13.

[12] Chandra, A., Crane, S. J., Tung, E. E., Hanson, G. J., North, F., Cha, S. S. \& Takahashi, P. Y. (2015). PatientReported Geriatric Symptoms as Risk Factors for Hospitalization and Emergency Department Visits. Aging and Disease, 6(3): 188-195. 
[13] Coderch, J., Sánchez-Pérez, I., Ibern, P., Carreras, M., Pérez-Berruezo, X. \& Inoriza, J. M. (2014). Predicción del riesgo individual de alto coste sanitario para la identificación de pacientes crónicos complejos. Gaceta Sanitaria, 28(4): 292-300. (in Spanish)

[14] Cowen, M. E., Czerwinski, J. L., Posa, P. J., Van Hoek, E., Mattimore, J., Halasyamani, L. K. \& Strawderman, R. L. (2014). Implementation of a mortality prediction rule for real-time decision making: feasibility and validity. Journal of Hospital Medicine, 9(11): 720-726.

[15] Doñate-Martínez, A., Garcés, J. \& Ródenas, F. (2014). Application of screening tools to detect risk of hospital readmission in elderly patients in Valencian Healthcare System (VHS) (Spain). Archives of Gerontology and Geriatrics, 59: 408-414.

[16] Doñate-Martínez, A., Ródenas, F. \& Garcés, J. (2016). Impact of a primary-based telemonitoring programme in HRQOL, satisfaction and usefulness in a sample of older adults with chronic diseases in Valencia (Spain). Archives of Gerontology and Geriatrics, 62: 169-175.

[17] Eddy, D., Adler, J., Patterson, B., Lucas, D., Smith, K. \& Morris, M. (2011). Individualized Guidelines: The Potential for Increasing Quality and Reducing Costs. Annals of Internal Medicine, 154: 627-634.

[18] European Commission (2015). Highlights and conclusions from the Conference "Which priorities for a European policy on multimorbidity". Available at: https://webgate. ec. europa. eu/eipaha/library/index/show/id/981 Accessed 10/12/2015.

[19] Fabbian, F., Boccafogli, A., De Giorgi, A., Pala, M., Salmi, R., Melandri, R., Gallerani, M., Gardini, A., Rinaldi, G. \& Manfredini, R. (2015). The crucial factor of hospital readmissions: a retrospective cohort study of patients evaluated in the emergency department and admitted to the department of medicine of a general hospital in Italy. European Journal of Medical Research, 20: 6.

[20] Fernández-Ruiz, M. L., Sánchez-Bayle, M., Fernández-Ruiz, S. \& Palomo, L. (2015). El efecto de los copagos sobre la adherencia a los medicamentos prescritos. Atención Primaria, 47(9): 606-607. (in Spanish)

[21] Foessa \& Cáritas (2013). Desigualdad y Derechos Sociales. Available at: http://www. caritas. es/imagesrepository/CapitulosPublicaciones/4551/Desigualdad\%20y\%20derechos\%20sociales. \%20Versi\%C3\%B3n\%20digital. pdf (in Spanish) Accessed 05/12/2015.

[22] Garcés, J. \& Ródenas, F. (2015). La gestión de casos como metodología para la conexión de los sistemas sanitario y social en España. Atención Primaria, 47(8): 482-489. (in Spanish)

[23] Garcés, J., Carretero, S., \& Ródenas, F. (2011). Readings of the social sustainability theory. Applications to the long-term care field. Valencia: Tirant lo Blanch.

[24] Garcés, J., Ródenas, F., \& Hammar, T. (2013). Converging methods to link social and health care systems and informal care - confronting Nordic and Mediterranean approaches. In K. Liechsenring, J. Billing, \& H. Nies (Eds. ), Long term care in Europe - improving policy and practice (pp. 110-117). London: Palgrave Macmillan.

[25] García-Goñi, M., Hernández-Quevedo, C., Nuño-Solinís, R. \& Paolucci, F. (2012). Pathways towards chronic care-focused healthcare systems: Evidence from Spain. Health Policy, 108: 236-245.

[26] Garin, N., Olaya, B., Perales, J., Moneta, M. V., Miret, M., Ayuso-Mateos, J. L. \& Haro, J. M. (2014). Multimorbidity Patterns in a National Representative Sample of the Spanish Adult Population. PLos ONE, 9(1): e84794.

[27] Hawton, A., Green, C., Dickens, A. P., Richards, S. H., Taylor, R. S., Edwards, R., Greaves, C. J. \& Campbell, J. L. (2011). The impact of social isolation on the health status and health-related quality of life of older people. Quality of Life Research, 20(1): 57-67.

[28] Hippisley-Cox, J. \& Coupland, C. (2013). Predicting risk of emergency admission to hospital using primary care data: derivation and validation of QAdmissions score. BMJ Open, 3: e003482. 
[29] Jakobsson, U., Kristensson, J., Hallberg, I. R. \& Midlöv, P. (2011). Psychosocial perspectives on health care utilization among frail elderly people: An explorative study. Archives of Gerontology and Geriatrics, 52(3): 290294.

[30] Kansagara, D., Englander, H., Salanitro, A., Kagen, D., Theobald, C., Freeman, M. \& Kripalani, S. (2011). Risk PredictionModels forHospital Readmission. A Systematic Review. Journal of American Medical Association, 306(15): 1688-1698.

[31] Lehnert, T., Heider, D., Leicht, H., Heinrich, S., Corrieri, S., Luppa, M., Riedel-Heller, S. \& König, H-H. (2011). Health Care Utilization and Costs of Elderly Persons With Multiple Chronic Conditions. Medical Care Research and Review, 68(4): 387-420.

[32] Lyon, D., Lancaster, G. A., Taylor, S., Dowrick, C., \& Chellaswamy, H. (2007). Predicting the likelihood of emergency admission to hospital of older people: development and validation of the Emergency Admission Risk Likelihood Index (EARLI). Family Practice, 24: 158-167.

[33] Merino, S. \& Cruz-Jentoft, A. J. (2012). Impact of hospital admission on functional and cognitive measures in older subjects. European Geriatric Medicine, 3: 208-212.

[34] Orueta, J. F., Del Pino, M. M., Barrio, I., Nuño, R., Cuadrado, M. \& Sola, C. (2013). Estratificación de la población en el País Vasco: resultados en el primer año de implantación. Atención Primaria, 45(1): 54-60. (in Spanish)

[35] Reuben, D. B., Keeler, E., Seeman, T. E., Sewall, A., Hirsch, S. H. \& Guralnik, J. M. (2002). Development of a method to identify seniors at high risk for high hospital utilization. Medical Care, 40: 782-793.

[36] Ródenas, F., Garcés, J., Doñate-Martínez, A. \& Zafra, E. (2014). Aplicación de The Community Assessment Risk Screen (CARS) en centros de Atención Primaria del Sistema Sanitario Valenciano. Atención Primaria 46(1), 25-31. (in Spanish)

[37] Salisbury, C., Johnson, L., Purdy, S., Valderas, J. M. \& Montgomery, A. A. (2011). Epidemiology and impact of multimorbidity in primary care: a retrospective cohort study. British Journal of General Practice, 61(582): e1221.

[38] Shelton, P., Sager, M. A., \& Schraeder, C. (2000). The community assessment risk screen (CARS): Identifying elderly persons at risk for hospitalization or emergency department visit. The American Journal of Managed Care, 6: 925-933.

[39] Sinnot, C., McHugh, S., Browne, J. \& Bradley, C. (2013). GPs' perspectives on the management of patients with multimorbidity: systematic review and synthesis of qualitative research. BMJ Open, 3: e003610.

[40] Sternberg, S. A., Schwartz, A., Karunananthan, S., Bergman, H. \& Clarfield, A. M. (2011). The Identification of Frailty: A Systematic Literature Review. Journal of American Geriatric Society, 59: 2129-2138 